\title{
The Levels of Availability of Electronic Learning Efficiencies of Yemeni Female Teachers
}

\author{
Fahad Sallam Al-Azazi*, Fang Min \\ Computer Science and Technology Department, Xidian University, Xi'an, China \\ *Corresponding author:632719602@qq.com
}

\begin{abstract}
Over the last few years, Electronic Learning use is becoming more widespread and successful in teaching female students in developing countries in general, and the Arabic world. This trend is seen especially with the introduction of new technologies for learning and teaching. As a result, the competent female teachers are the key for it's successful implementations, and they must have the sufficient knowledge and skills for the effective implementation of Electronic Learning. So, this study aims to evaluate, identify the practice, knowledge levels, and the efficiencient use of Electronic Learning by Yemeni female teachers at Al-Hodaidah city schools. Furthermore, it tried to determine whether there were differences in those female teachers' best practice and knowledge level due to the (Academic Specialization Type; Academic Qualifications; Educational Courses Attended Related to Electronic Learning). A questionnaire (40 items) containing four axises of Electronic Learning efficiencies (Computers Use Skills; Networks and Internet Use Skills; Knowledge of Electronic Learning Culture; Skills of Design and Managing the Curricular of Electronic Learning) was used. The sample consisted of (174) female teachers chosen randomly out of the study community. A descriptive approach was used, also SPSS program for data analyses. The study revealed a moderate level of practice, knowledge, and degree of efficiencies of Electronic Learning. The usage and knowledge level of the networks and internet use skills had the highest degree among all best practices, whereas the design and managing the Electronic Learning curricular skills got the least degree of all best practices. Additionally, there were no statistically significant variances and differences found due to the types of academic qualifications in the third and fourth axises. But there were statistically significant differences found due to the type of academic specialization, types of academic qualifications and attending training course related to Electronic Learning on all the axises.
\end{abstract}

Keywords: electronic learning, skills, efficiencies of electronic learning, Yemeni female teachers

Cite This Article: Fahad Sallam Al-Azazi, and Fang Min, "The Levels of Availability of Electronic Learning Efficiencies of Yemeni Female Teachers." American Journal of Educational Research, vol. 5, no. 6 (2017): 660-676. doi: 10.12691/education-5-6-12.

\section{Introduction}

With the growing role and effect of technology in the education of society, the Electronic Learning has become an important topic in teaching and learning, hence the role of teacher and student alike. This is resulting from the fact that this solution makes it possible for students to complete and finish their education, without the sitting inside the traditional classroom. Additionally, it has many different solutions, which can present them to solve the various education problems. Although the situation of education in Yemen has many problems, but the use of education technology and Electronic Learning in the education of Yemen is still in its infancy, and among the most important of these problems are the female education, and the little use of Electronic Learning amongst their teachers as like the most developing countries [1].

However, in the previous years, the Yemeni government has sought to provide free education and compulsory to female and male students, in most provinces, through the emphasis on providing the requisite schools with the basic possibilities in the infrastructure, which will help them to complete their schooling since childhood. Due to the educational opportunities availability at an early age to all students is critical to success the education, especially female for more development, studies have shown that "There is no tool for development more effective than the education of girls," Kofi Annan, the former UN Secretary-General (2005) [2]. Thus, Yemeni education saw an incredible period of improvement and growth. The enrollment rate of Yemeni students rose from 71.3 percent to 97.5 percent during this period, an incredible stride, according to The World Bank [3].

Nevertheless, Yemen has been considered have the minimal rights to the female' education [4,5]. Nearly half of Yemeni females attend primary school while two out of three female in the Yemen are illiterate, according to UNICEF statistics [5]. There are many reasons which led the Yemeni families to refuse to attend their daughters at school, for example, most schools don't have a sufficient number of female teachers to teach large numbers of 
female students, as a result of this the families often refuse to let male teachers teach their daughters. Additionally, early marriage, preoccupation with housekeeping burdens, limited income, illiteracy, also the social barriers which are against female traveling alone prevent many of them from studying away from the family home $[2,5]$.

Since March 2015 until now, the situation of country's education system is more deteriorating, because more than two million female and male students out of school, with 2108 schools have been damaged because of the Yemeni' civil war, which causes internal and external displacement, the UNICEF estimates [6]. Additionally, students have been killed while attending classes as well as on their way to school, this compels most families to rethink about the safety of pursuing education, especially female education. Consequently, this leads to increase the problems of educations of female students [3].

Nevertheless, in light of the rapid development of technology in the field of education, education can continue in humanitarian emergencies, conflicts and after the normal life returns, via Electronic Learning. Electronic Learning will provide more support to meet the mounting needs of female and male students and their families at risk of losing the access to the necessary education in contexts that are out of school, or they cannot access to learning. So, the female students can access to their own education from anywhere, at any time, no matter if the distance far to school, whatever circumstances, and safely. Therefore, the challenges of females' education at Yemen prove to be continual issues at a time of the peace and conflicts.

The challenges of females' education at Yemen and developing countries prove to be continual issues at a time of the peace and conflicts. Electronic Learning is an important stage of evolution integrates traditional education (face-to-face classroom) with the web- based contents to try and improve accessibility for all learners with many advantages as: freedom of choice the (Cost, Time, Place) [7]. So, for this reason it considered as suitable tools for learning female students. Knowledge creation in the learning process is an indivisible part of the works of teachers, because it is a process similar to experiences related to the selection of learning content which is more convenient in Electronic Learning, tailored to the needs and ambitions of Yemeni female students. But this work needs also other types of practices and skills which called efficiencies of Electronic Learning.

The efficiencies issue is related to the movement of a specialization in the field of teacher' education and training in all the countries, it has become like a response to the conventional trends in education based on the provision of female teachers with a considerable amount of general knowledge and academic culture, besides the practical training. Additionally, it's seen as a new way in the modern trends in the preparation of the modern teacher [8]. According to the findings of several studies, the gender variations was always a controversial topic, and efficiencies of Electronic Learning are no exception, where female teachers respondents gave a more positive answer than males, such as study Russell and Bradley (1997), Yuen and Ma (2002), and Teddy \& Paula, (2007), As researchers of the current study have already noted in the literature review [9]. Efficiencies are prepared via executing task analysis of the seniority and work or the experience length [10].

Wherefore, measure mastery level of specific efficiencies of Electronic Learning which owned by female teachers, will help them to enhance and increase their skills and capabilities in this field. In addition to, it will help the decision-making center at Yemen and the international organizations to know where to begin and what they need to investigate the idea of using Electronic Learning in the education of female students.

\section{Literature Review}

\subsection{Electronic Learning}

The education through Electronic Learning is different, due its nature is different from other forms of education in that students are separated of physically and socially from their teachers, their classmates, peers and the schools [11]. It can give female teachers the chance to give courses to large numbers of female students or girls who are unable to access the places of the curriculums due to restraints of the place or time. Also, it helps interaction between female teachers and learners, inside or out classrooms, with augmenting the possibility of the self-learning Additionally, it enables female students to prepare, equip assignments through use e-libraries with the additional sources online (Cooper \& Haney, 1999) [12].

In reality, the definitions of Electronic Learning are simple but also assorted. So, there are several definitions which tried to describe Electronic Learning, such as internet learning, online learning, computerized Electronic Learning, handing over instruction via the Internet, distance education and many others definitions. In general, it is learning by harnessing the advanced technologies to access curriculum of educational whether inside or outside of a traditional classroom.

Whereas Henry, (2001) says that Electronic Learning is all the suitable applications which using the internet for the teaching process and cover all skills and knowledge through the comprehensive approach that bring learning about via the web technology and the internet $[8,14,15]$.

Additionally, it depends on some concepts such as active learning, self-directed learning, independent learning, and work-based learning, and education based on the problem, according to $[16,17]$. Moreover, it supplies varied environments for students with interactive, dynamic, and accessibility nonlinear system to a big range of information such as animation, graphics, and text, according to $[17,18]$. In most definitions, it indicates to a course, curriculum, degree or program delivered completely via the internet [18].

Therefore, according to the earlier definitions mentioned, and in the light of the present study, the researchers of the current study are defined the Electronic Learning. It is like any use of the technology of the internet and the web, that bring data or information, or both of them together. Which includes text, graphics, animation, audio, video, to the learners' device, with interactive between them and female teachers who have the basic efficiencies of Electronic Learning, through the various of the devices and the Internet services. To 
support and improve the female students' education, to anywhere and anytime, whether synchronously or asynchronously.

\subsection{Efficiencies}

In general, Efficiencies has been defined as "the perspectives collections", which can apply in a various of fields, as Management Theory, Human Resource Management, Psychology. Also including Education, according to definitions of the specialists, which are based on the focusing on their work, according to define of Hoffmann, (1999) [19]. But the definition of Parry, (1998) efficiencies are sets of abilities, skills, and knowledge [19]. That are related to the performances of effective in the roles and the missions, which are at hand, cited in [19]. On the other hand, enhancing teaching experiences of female teachers has become more important in education, due to increased female students who not enroll in schools. Also, continuing professional improvement is fundamental to being a role model for learners of female teachers and for more effective usage of environments of teaching technological.

In general, efficiencies are not static only but also continually change their situations according to other things, that are depended on knowledge, which contained values, experiences, abilities and comprehended on the volition basis, according to define of Erpenbeck, (2003) cited in [21]. However, the quality development of efficiencies of who teach cannot exist without creativity because the creativity of teacher is one of the important core factors of teaching students. As creativity is a crucial factor in the multidimensional development of teachers' professional efficiencies, according to (Sternberg, 1996) and (Amabile, 1996) [20]. In reality, there are many authors discussed the concept of efficiency in general and efficiency of Electronic Learning in specific, also, they have studied and made proposals considering the efficiencies besides jobs of the teachers who share or join into the programs of teaching in virtual environments.

While, efficiencies are groups of abilities, skills and related knowledge which correlate beside effective performance in the roles or tasks which are at hand $[20,19]$. But, based to define of [23], efficiencies are the cases that are being qualified to implement a task, activity or function of the job, and efficiency as the way which a case of efficiency can be evidenced to the relevant community [23,24]. In parallel with these definitions, AlFarra, (1989) describes efficiency as the comprehensive behavior of the teacher containing skills, knowledge, and attitudes obtained after enrolment in a specific approach whose impact is reflected in his achievement, which is measured by specific tools specifically developed for this mission, Cited in [8].

Notably, identifying the efficiencies and roles of schools' female teachers in virtual environments is crucial to females' education schools, in order to build a common frame for training initiatives and teaching. Additionally, there is a necessity to integrate a range of different efficiencies, emphasize about the performing of teachers with online ought to follow a multidimensional role [23]. Correspondingly, It is important to take into mind that design of virtual education, assessment, and development can include exceptional features and, but also need specific tasks in teaching [23]. Consequently, it is important to evaluate all the changes and differences which the teaching in virtual environments require for the female teachers, in all levels of both schools and universities. Also, Rothwell \& Lindholm, (1999) believe that Measurement and identification the efficiencies are useful for the educators, educational practitioners, and potential employers, due determining efficiencies help to improve the performance of human and integrate individual skills with organizational core efficiencies [13]. Several studies recommended about preparing the teachers with more interesting in the efficiencies of teaching and Electronic Learning, as [13,39,56,58].

Similarly, several conferences in the Arab World have asserted the importance of developing and training the female teachers' efficiencies, such as: The Fourth International Conference for Electronic Learning and Distance Learning at KSA in 2015, where addressed the improvement and development of female teachers' performance skills and theoretical knowledge, at the general schools and universities, with an emphasis on the significance of doing so [24]. Additionally, the Conference of Women and Electronic Learning, at Ajman University in 2010, called to improve teaching and learning of female teachers and female students, comprehensive training for them, developing the skills of workers in the fields of educational, and introducing the housewives and working women in particular to training in Electronic Learning education to continue their education at a place and time suitable for their lifestyle. In other words, emphasis on the significance of paying more attention to the efficiencies of teaching and learning for females [25].

\subsection{Efficiencies of Electronic Learning}

In relation to Electronic Learning efficiencies, the teacher play a very important and critical role inefficiencies of Electronic Learning, due to the diversity of roles and the skills which the teacher must be able to do them, according to summarize the previous studies by [26] the most important roles of the teacher in Electronic Learning as follow, Researcher, Technologist, Content Presenter, Coordinator, Counselor, Facilitator and Assessor [26]. So, the female teachers will be more distinguished via the professional efficiencies and distinctive teaching aids, as well as the support of the general field of their specialization, or the specific of their specialty field. Correspondingly, there is an important fact is Female Teachers' success in using Electronic Learning applications depends on their previous experience of technical in the field of information technology [27]. On this topic, based on the study Alexander and McKenzie, (1998) proposed investing more and more into the education-related training of teachers at schools, because they act as a guide to introduce Electronic Learning at their schools through much more technical skills might be necessary, an issue that has to be seen at regarding Electronic Learning training, as a sign of the efficiencies of Electronic Learning [28].

Hence, Efficiencies of Electronic Learning have also many definitions due to the differences in notions of the 
expert persons. For instance, according to define of [19] efficiencies of Electronic Learning are the requisite skills, understandings, knowledge, behaviors and attitudes which required for the effective performance [19]. According to define of [8] efficiencies of Electronic Learning as a group of capabilities, attitudes, knowledge, and skills that who teach should own, and apply during the place of tuition contexts implementation using any of the Electronic Learning tools whether asynchronously or synchronously.

As also mentioned by Jad and Mahmoud, (2007) Electronic Learning efficiencies as a group of knowledge, skills, and attitudes relevant to Electronic Learning, and its use indispensable to shape educational frameworks easily and readily, by the using electronic aids to attain their goals of educational, cited in [8,14]. While [31] mentions that efficiencies of Electronic Learning are systems of an educational to evaluate the trainees or learners' programs and educational of training at any place using the interactive information and communication technology (ICT) as the intranet, Computer, E-Mail, CDs, ...etc. [8,31]. In addition, [11] noted that efficiencies are significant because they assist as tools that for determine knowledge, skills, and behavior which is needed to effectively perform a role, and a key efficiency in Electronic Learning is the ability to make an environment where students can communicate with the teachers and with each other. In identifying the efficiencies and the roles of Electronic Learning professionals, Thach and Murphy (1995) reminded that skills of technical and communicating play a critical role in Electronic Learning [11].

As also noted by Davis and his colleagues (2007), in the course of Electronic Learning the teachers should have and own more knowledge, skills, and qualities, about technological innovations, than a traditional teacher does, and all these skills, knowledge, and qualities are systematically creating the teachers' efficiencies who want to teach online [22]. Consequently, Electronic Learning efficiencies educationally are described through the researchers of the present study as a necessary collection of knowledge, experiences, skills, capabilities, and behaviors which the female teachers should own, before and after any chances for them to know and learn any new techniques, which can be employed to positively effect on achievement and education of female students, during the using and Applying the Electronic Learning to enhance their education, from anywhere and at any time.

\subsection{Categories of Electronic Learning Efficiencies}

The classification of Electronic Learning efficiencies is very important to facilitate and improve the analysis of the essential and important efficiencies by identifying which the efficiencies required for more effective performance to execute the various Electronic Learning environment. In addition, the successful performance in environments of Electronic Learning has been shown to require success in the several a range of domains. In order to achieve that, during the last decade, there are several international organizations and many studies have been provided various proposals concerning to the Electronic Learning efficiencies categories, which the teacher who participates in programs of teaching through Electronic Learning environments needs to own them. One of these international organizations was the (International Society for Technology in Education - ISTE), which had determined the (National Educational Technology Standards for Teachers- NETS.T) according to the second edition in 1977, categorized the efficiencies into (three categories) namely: firstly, the Basic Skills of Computer/Technology Operations and Concepts; then the Professional and Personal Use of Technology; and finally, the Instruction' Technology Application. But the third edition in (2000 - 2002) organized the Standards into six axises which the teachers should know, also be able to do, namely:

- Concepts \& Operations of the Technology related.

- Planning \& Designing of the Experiences and Effective Environments of Learning by technology related.

- The Learning, Teaching, and Implementing of the plans and strategies of Curriculum by technology related.

- The facilitating of the effective of the evaluation and assessment strategies by technology related.

- The enhancing of the Professional Practice and Productivity by technology related.

- The Understanding of the issues of Legal, Ethical, Social, and Human, which related to technology use [30].

Similarly, the standards of teachers' (Information and Communication Technology-ICT) skills, which classify into eight categories to develop the teachers' efficiencies of ICT, which combine the ICT skills and Electronic Learning skills, according to the (UNESCO, 2006-2008) [33,34], namely:

1. Basic Computer/Technology Concepts and Operations.

2. Professional and Personal Technology' Use.

3. Application of Technology in Education.

4. Issues of the Ethical, Social, and Human.

5. The tool of Productivity.

6. Information Access and Telecommunications by using resources of telecommunications and information-access to the instruction' support.

7. Research, Solving of Problem, and Product Development.

8. Skills of Information Literacy.

In addition, there are other related to Standards Quality Online Teaching, which produced in United States of America (USA) by the Educational Technology Cooperative of the Southern Regional Education Board (SREB) in Atlanta, (2006); the American Society for Training and Development (ASTD) in the USA, (2001); the International Association for K-12 Online Learning (iNACOL), which has determined the Quality Online Teaching National Standards of or Quality Online Teaching, (2007); and other international organizations which focused on the teachers of traditional schools in secondary and primary, and sets categories of Electronic Learning efficiencies standards [35,36].

But although all the differences between the organizations and authors' proposals, there are several similarities between of their categories, which can be 
determined, and these similarities are related to the build the authors to their proposals based on the proposals of others, or due to the commonalities from their vision to the teachers' efficiencies required [23]. In the following, some of their lists are presented to give a more clear view of those categories, according to some of the classifications of various studies and international organizations.

For instance, [37] categorizes the Electronic Learning' efficiencies into a set of skills namely, teaching planning, educational technologies, evaluation, feedback, interior design, and online design [11,37,38]. Whereas [35] secreted the efficiencies of Electronic Learning into four domains: the electronic calendar of student performance and educational programs, the using of the computer, the design of software and web and the using of the online networks domain. In addition, [36] classify the efficiencies into four axises namely, Electronic Learning cultural, computer driving, Internet and networks driving, and the using of educational multimedia programs.

In the same frame, [12] assort the female teachers' efficiencies into four sets namely, using computer, networks and internet driving, Electronic Teaching culture and multimedia design. Also, [28] classified the efficiencies to four skills types as follows, computers using, network services using, e-course designing and ecourses administrating.

While, [37] divides the female teachers' efficiencies of Electronic Learning to three fields as follows: use a computer, use the internet and use Management e-courses. Likewise, the study [38] identified the Electronic Learning efficiencies into three various items relating to the basics of computer, the internet using and finally the using of computer softwares. As well the study [39] distributed the Electronic Learning efficiencies into three groups of skills the first one is the computer using, then the sources Internet using, and finally the information \& communication technology using and evaluating the social studies.

There are several Arabic and foreign types of researches were performed to determine and give a more clear idea about each one of these groups and categories which previously mentioned and related to efficiencies of Electronic Learning, where the most studies focused on determining specific Electronic Learning efficiencies issue. Collecting all these various issues jointly can give an overview of Electronic Learning image and its requirements like knowledge and skills. Firstly, Arabic studies from the Middle East and North Africa, for example: [44] pursued to characterize the efficiencies of Electronic Learning, which are necessary to teach courses of Islamic education at secondary schools in Jordan. Where the questionnaire of (76) items distributed into six axises was developed, and the study population consisted of (40) male and female teachers. Findings uncovered there were statically significant differences in teachers evaluation the importance of efficiencies due to the academic Specialization type and attendance on training courses in favor of these who have the attendance of education sessions and humanistic qualification [40].

And, [40] aimed to recognize the availability level of efficiencies of Electronic Learning among the Saudis teachers of the secondary schools at Al-Mekhwah educational governorate. Where the questionnaire consisted of (45) efficiencies distributed into four axises was developed namely (Electronic Learning culture, computer driving, the Internet and networks driving, programs and educational multimedia), and the study community consisted of (306) teachers. Findings exposed that estimations of the study community of the Electronic Learning efficiencies availability degree were moderate. Also, there are significant differences between the answers of the study community due to the experience years in favor of the teachers who have the modern service. In addition, there are significant differences were found due to specialization in the axis of computer driving efficiencies in favor of the scientific qualification. Besides, there aren't significant differences between the answers of the study community due to the training courses [36].

Whereas, [48] that aimed to reveal the appreciation degree of the extent of the importance the efficiencies of educational technology to improve the male and female science teachers' professional performance at the Jordanian public schools in Al-Karak province, in the study variables light: specialization, experience, and qualification. To implement the goals of the study the researcher used a questionnaire consisted of (117) skills divided into seven domains, then distributed to a specified sample of (92) teachers. The study results showed highly level in the appreciation degree of the extent of the importance the skills of educational technology which were in the questionnaire from the point view all the teachers. Also, the study indicated no statistically significant differences attributed to the gender, specialization, training courses and qualification. Findings also uncovered there were statically significant differences in teachers evaluation the importance of these skills due to the gender and experience in favor of females and these who have long years of experience [48].

But, [41] study aimed at identified the degree of the male and female teachers' needs for these efficiencies of Electronic Learning in field computerized interactive learning (CIL), at schools in Gaza and analyzed its relationship with their attitudes at the UNRWA schools [39]. Where the study used two questionnaires, the first questionnaire consisted of (43) efficiencies distributed into four main areas was developed namely (Electronic Learning culture, Internet website Leadership, Software and learning media design, and Computer operation), also the second questionnaire consisted of (27) attitudes' items, distributed to the study community consisted of (62) teachers. The study findings showed the estimated level of the availability of Electronic Learning International Board of Standards efficiencies teachers was at the high level. Also, the attitude of teachers towards (CIL) program existed at the high level. While, there is no difference between the mean levels of male and female teachers in the (The Internet Website Leadership, software and learning media design) areas. And, there are no statistically significant disparities between all areas of efficiencies of Electronic Learning, according to the number of years of service. As well, there are no statistically significant disparities between the level of efficiencies of Electronic Learning availability and the attitude towards a degree(CIL), moreover there was any relationship statistically significant between them, where the more efficiencies, the more positive attitude towards (CIL) is indicated [42]. 
While, [47] examined the extent of acquiring the efficiencies of Electronic Learning which should be owned by male and female teachers who are teaching computer at the King Hamad's project schools in the Bahrain. To achieve the study objectives designed a questionnaire consisted of (52) skills covered five axes, in light of gender, job title, and teaching experience. And the study sample consisted of (160) teachers. The study results revealed statistically significant differences according to the teaching experience effect through all axes except in the axis of The Manage Electronic Learning Ability, and The Evaluate Ability, in favor for (ten-year) teaching experience. Also, referred that there were no statistically significant differences due to the impact of job title on all the axes except in the Electronic Learning technique using axis. Moreover, the findings showed that there were no statistically significant disparities due to the gender on the five axes as well as on the questionnaire as a whole the findings showed that there were no statistically significant disparities due to the gender on the five axes as well as on the questionnaire as a whole [43].

Similarly, [26] sought to know the mastery level of efficiencies of Electronic Learning among the teachers who are teaching technology courses in schools of Gaza governorate, to accomplish the study, the researchers prepared a questionnaire of (69) skills divided into four main domains, distributed over a sample of (82) male and female teachers. The study results revealed there were no statistically significant disparities due to the majors or the experience years. Additionally, there were statistically significant disparities due to the grades on all the axes of study, except the basics of PC use. Moreover, the findings of the study showed that teachers possess these efficiencies as follows, firstly the fundamentals of PC using the percentage was (82\%), secondly the services of the network (76\%), thirdly designing E-course (66\%), and finally administrating e-courses (64\%) [26].

Also, [44] checked the ability degrees of Electronic Learning efficiencies, in the necessary skills for using the computer, the internet, and managing e-assignments, among the Arabic language female teachers at secondary schools of Kingdom of Saudi Arabia, to achieve the study objectives the researcher used a questionnaire of (39) skills, distributed over a sample of (24) teachers. The findings indicated that the degree of the skills proficiency required for using the computer was low, and the level of using the internet was medium, while their level of the ecourses managing was good. Besides, the study specified no statistically significant discrepancies attributed to the experience [44].

Besides that, [45] endeavoured to determine the availability degrees of information and communication technology efficiencies among male and female teachers of social studies in several post basic education schools at Omani governorates. Whilst, [46] the objective of this study was to determine the exercise degree of the teaching skills which are important to use the Objects of Digital Learning according to a range of perspectives among the male and female teachers who are teaching the courses of the information and communication technology at secondary schools of Gaza strip. In the same frame, [47] tested to what degree of the computer skills used in teaching mathematics courses among male and female teachers of basic elementary at UNRWA schools in Gaza Strip.

On the other hand, [48] aimed to investigate the elements and factors that impact on the success, development, and implementation of Electronic Learning, to choose the most appropriate framework, to use it in secondary schools at Bahrain. Also, discussed the differences between the characteristics of male and female students in the skills of computers, attitudes, and motivation; then discussed the differences between characteristics of male and female teachers in some axises such as attitudes, technology control, pedagogy, teaching style, quality of technology, the effectiveness of infrastructure, and design the content [48].

In addition, [12] aimed to recognize the availability level for the efficiencies of Electronic Teaching among male and female teachers of Arabic language in the schools of Al-Hisa educational directorate at Jordan, the study emphasized the importance of these efficiencies as a basis for Electronic Learning experience, and the importance of having teaching efficiencies in general Electronic Teaching and Electronic Learning in specific by teachers.

[49] study aimed to understand the situation of using the (Classera) which is Learning Management Systems (LMS), also tried to explore the challenges of Electronic Learning in Saudi Arabia at K-12 schools in Riyadh city. The study covered the (12) public schools that had adopted and implemented Classera. The sample consisted of (70) teachers where the researcher used an online survey was used to gather data. The study has demonstrated that most teachers in those public schools are satisfied with the Classera implementation in their classrooms. Nevertheless, those teachers will not totally benefit from the privileges of applying Classera in teaching and learning, unless whole challenges are taken into consideration.

Secondly, foreign studies from differents countries, such as:

[50] study focused on the structure of efficiencies of information and communications technology for teachers and students, with their development in secondary and primary schools in the Republic of Czech, also identified the current state, the curriculum structure [50]. The sample was composed of 3,500 schools randomly to the realization of the research project. According to the study findings, efficiencies were divided into five fields focused on the characteristics of informatics learning activities namely: (Characteristics of informatics learning activities, Content of informatics subjects, Concept of information technology efficiencies development and its status, Structure of teachers' information technology efficiencies, and Implementation of digital technologies into the school learning environment) [50].

[55] study examined the differents in teachers' Electronic Learning efficiencies [8]. A questionnaire was developed to examine the Electronic Learning efficiencies of vocational high-school teachers in North Cyprus. The independent variables used were teaching experience, Internet access, ICT teacher/non-ICT teachers, Electronic Learning training needs, geographic location, and status. Results showed that the Electronic Learning efficiencies 
of teachers at North Cyprus could be distributed depending to web-based Electronic Learning, administrative Electronic Learning, and technology-based Electronic Learning. Additionally, there is Electronic Learning distribute between that teacher who are skilled and those who are not, those who have restricted Internet access and those who have limited access to the Internet, those who have insufficient training needs and those who have more practice and training needs, and between teachers' ICT and non-ICT teachers [8,54].

Teddy \& Paula, (2007) study tried to identify and evaluated the factors affecting the Electronic Learning readiness of teachers at Hong Kong's schools, the researcher used a questionnaire of (29) questions were distributed to 200 teachers [9]. Also, recognized the availability degree for the efficiencies of IT to use technologies of Electronic Learning among students. Findings presented variations in perceived readiness between secondary school and primary school teachers; male and female teachers. And that primary students do not have sufficient IT efficiencies to use Electronic Learning Technologies, female teachers' respondents gave a more positive answer than males. Interestingly, teachers' and students' readiness to accept and adopt Electronic Learning in Primary and secondary schools [9].

The topic of Electronic Learning efficiencies and the Electronic Teaching efficiencies attracted the interests of researchers, where several studies were conducted on this topic in many countries; As a result, the previous studies emphasized the importance of having Electronic Teaching efficiencies in general, and Electronic Learning efficiencies in specific by teachers. All the researches and studies that have conducted didn't discuss the topic of Electronic Learning efficiencies of female teachers in Yemen; because, there is rareness of studies of this topic, especially in regard to the efficiencies of schools' female teachers. So, this study is distinct and different than the previous studies in that it focused on efficiencies of Electronic Learning for female teachers in all stages of schools at Yemen.

\section{Problem of Study}

It is very important for the female teacher to possess the essential efficiencies of Electronic Learning necessary for the accurate performance of her job. In Yemen, most schools are thinking to adopt Electronic Learning while instructing. Therefore, it is very important to identify to what level or extent female teachers practice and knowledge those efficiencies of Electronic Learning to ensure their level of readiness to practice their roles as effective as desired. Thus, the problem of the present study is represented in the identification of the situation of female teachers' practice and knowledge degree of efficiencies of Electronic Learning at Al-Hodaidah schools. Therefore, they need certain efficiencies during the course such as working as facilitators.

Several of the needed efficiencies will be useful after the course has concluded. For example, if the course platform uses an online grade book, the instructor ideally should be able to transfer the grades for transmittal to the school registrar, (Smith, 2005) [8]. The prime contribution of this research is that it addresses the first step to the success of Electronic Learning in the schools' sector in Yemen, because there is a lack of theoretical and empirical studies in this field in this country. The efficiency level of female teachers is very important for the benefit of education and society in general, and females' education in particular and refugees also. It is evident that a distinguished school female teachers, as mentioned earlier, are one of the most paramount and important pillars of the females' educational system of school when based on Electronic Learning. The intention of this research is to knowing and understand which the efficiencies are the female teachers needed to be more effective in Electronic Learning and how can we help them to acquire these skills and knowledge.

Therefore, the present study is seen important because it addresses a very important aspect of Electronic Learning represented in the female teacher himself and her mastery level of Electronic Learning specific efficiencies. The success of a female teacher is, no more judged by her scientific specializations but by the level of her knowledge of efficiencies of Electronic Learning and her ability to implement them in the Electronic Learning environment as has been recommended by a set of scientific conferences in this field. Scientific conferences, in addition to a set of seminars are also interested in the improvement of Electronic Learning. They have emphasized the importance of the provision of efficiencies of Electronic Learning among female teachers such as the Fourth International Conference for Electronic Learning and Distance Learning at KSA in 2015, and the Conference of Women and Electronic Learning at Ajman University in 2010 [26]. In short, the present study, as well as other studies that investigated the efficiencies of Electronic Learning, is consistent with the trends that call for the development of such efficiencies among female teachers.

\section{The Study Questions}

The study intended at answering the following questions:

1. To what degree do female teachers at Al-Hodaidah city schools practice the efficiencies of Electronic Learning?

2. What are the female teachers' efficiencies of Electronic Learning that have the highest and the lowest practice and knowledge indicators?

3. Are there any statistically significant variances and differences $(\alpha=0.05)$ in the practice and knowledge degrees of female teachers at Al- Hodaidah city schools due to the type of academic specialization, types of academic qualifications, and Electronic Learning training courses?

\section{The Study Hypotheses}

After reviewing the previous studies in this research field, the following hypotheses were put forward:

- First Hypothesis: "There are no significant differences at $(\alpha=0.05)$ the 1 nd and 2 nd axises degree of the Electronic Learning efficiencies and their dimensions 
about (the computers use skills, and the networks and internet use skills) for female teachers at AlHodaidah city schools due to the type of academic specialization and Attendance on training courses' variables."

- Second Hypothesis: "There are no significant differences at $(\alpha=0.05)$ in the 1 st and 2 nd axises degree of the Electronic Learning efficiencies and their dimensions about (the computers use skills, and the networks and internet use skills) for female teachers at Al-Hodaidah city schools due to the types of academic qualifications."

- Third Hypothesis: "There are no significant variances and differences at $(\alpha=0.05)$ in the Third axis degree of the Electronic Learning efficiencies, which its dimensions about (the knowledge of Electronic Learning culture) for female teachers at Al-Hodaidah city schools due to the type of academic specialization, and Attendance on training courses’ variables.”

- Fourth Hypothesis: "There are no significant differences at $(\alpha=0.05)$ in the third axis degree of the Electronic Learning efficiencies, which its dimensions about (the knowledge of Electronic Learning culture) for female teachers at Al-Hodaidah city schools due to types of academic qualifications."

- Fifth Hypothesis: "There are no significant differences at $(\alpha=0.05)$ in the 4 th axis degree of the Electronic Learning efficiencies, which its dimensions about (the skills of design and managing the Electronic Learning curricular) for female teachers at Al- Hodaidah city schools due to the type of academic specialization and Attendance on training courses' variables.”

- Sixth Hypothesis: "There are no significant differences at $(\alpha=0.05)$ in the 4 th axis degree of the Electronic Learning efficiencies, which its dimensions about (the skills of design and managing the Electronic Learning curricular) for female teachers at Al- Hodaidah city schools due to the types of academic qualifications.”

\section{The Study Aims}

The present study aimed to:

1. Identify the efficiencies of Electronic Learning necessary for female teachers at Al-Hodaidah city schools.

2. Identify the practice and knowledge degree of necessary efficiencies of Electronic Learning among female teachers at Al- Hodaidah city schools.

3. Identify the effect of type of academic specialization, types of Academic Qualifications, and Electronic Learning training courses on female teachers' practice and knowledge degree of efficiencies of Electronic Learning.

4. Design an instrument by which efficiencies of Electronic Learning of female teachers can be measured.

5. Conclude findings that may contribute to the help of Electronic Learning stakeholders at Al-Hodaidah schools to make decisions that may improve the performance level of female teachers.

\section{Methodology}

The study follows the descriptive method because it is suitable for the nature of this study as it depends on studying the reality of the phenomenon and cares about describing it accurately besides expressing it in a qualitative or quantitative way. The community of the present study consisted of all female teachers (470) at Al-Hodaidah schools in the Educational year 2015- 2016.

\subsection{A. Instrument of Study}

For the sake of accomplishing the study aims, the researchers of the present study revised the theoretical literature and instruments included in previous studies.

Their experience in the field of Electronic Learning was also very helpful in this aspect. Therefore, a two-part questionnaire of Likert's type was developed.

The first part involved general information related to study variables, namely type of academic specialization, types of Academic Qualifications, and Electronic Learning training courses. The other part consisted of (40) items distributed to four main axises of Electronic Learning efficiencies.

The first axis consisted of the computers use skills.

The second axis involved the networks and internet use skills.

The third axis was the knowledge of Electronic Learning culture.

The final axis included the skills of design and managing the Electronic Learning curricular. The instrument was validated through its presentation in its primary version to a group of sixteen specialists in the field of Electronic Learning and Educational Technology. All arbitrators ensured that its fitness to the study and measures its aims. Suggestions and modifications of arbitrators were highly considered by the study researchers. In order to ensure the reliability of the study instrument, the researchers applied it to an exploratory sample of (30) persons from outside the study sample. Cronbach's Alpha Reliability Test to the four main axises was calculated and was (0.892). All degrees are accepted considering they are more than (0.60). In other words, such degree was appropriate for the study application.

\subsection{B. Procedures of Study}

After verifying the tool validity and reliability, the researchers distributed 400 questionnaires to female teachers in $\mathrm{Al}$-Hodaidah schools at the first semester of the Educational year 2015-2016. Only (174) questionnaires were back.

Finally, 174 questionnaires were accepted and analyzed statistically. Table 1 shows participants distribution and study variables.

The data were analyzed using the program of (SPSS). Means, percentages, MANOVA and standard deviations were used to measure the practice and knowledge level of efficiencies of Electronic Learning among female teachers at Al-Hodaidah city schools. MANOVA test was used to identify the effect of the independent variables, which were the type of academic specialization, types of 
Academic Qualifications, and Electronic Learning training courses in the practice and knowledge level of efficiencies of Electronic Learning among female teachers at Al-Hodaidah city schools. Mean scores were estimated by the following Table 2.

Table 1. The Sample Description

\begin{tabular}{|c|c|c|c|}
\hline & Categories & Frequency & Percentage \\
\hline \multirow{2}{*}{$\begin{array}{c}\text { Type of Academic } \\
\text { Specialization }\end{array}$} & Scientific & 91 & 52.3 \\
\cline { 2 - 4 } & Humanistic & 83 & 47.7 \\
\hline \multirow{3}{*}{$\begin{array}{c}\text { Types of Academic } \\
\text { Qualifications }\end{array}$} & Diploma & 37 & 21.3 \\
\cline { 2 - 4 } & Bachelor & 133 & 76.4 \\
\cline { 2 - 4 } & Master or Above & 4 & 2.3 \\
\hline \multirow{2}{*}{ Training Courses } & Yes & 107 & 61.5 \\
\cline { 2 - 4 } & No & 67 & 38.5 \\
\hline \multicolumn{2}{|c|}{ Total } & 174 & 100 \\
\hline
\end{tabular}

Table 2. The Means Value Estimation

\begin{tabular}{|c|c|c|c|c|}
\hline Very High & High & Medium & Low & Very Low \\
\hline $4.21-5.00$ & $3.41-4.20$ & $2.61-3.40$ & $1.81-2.60$ & $1.00-1.80$ \\
\hline
\end{tabular}

\section{Results}

This section deals with data analysis, presentation of results. It attempts to answer the questions of research. It also tests whether the study hypotheses will be rejected or retained. The statistical tests adopted in this study are:

the $\mathrm{T}$ - test One Sample used to show the difference in means between the whole sample and the hypothetical mean - $T$ value, the One-Way ANOVA, which is sufficient for presenting the variances and differences between more than two independent groups and Scheffe test to identify the most effective factor.
In addition to the basic descriptive statistical procedures Mann-Whitney U test, and Kruskal-Wallis test were also used in the study for comparison of the nonparametric features, and the medians. The Mann-Whitney $U$ test is used for comparing non-Normal variables for two groups, but the Kruskal-Wallis test for more than two groups samples.

\subsection{Results Related to the First Question}

Findings related to the first question:

To what degree do female teachers at Al-Hodaidah city schools practice the efficiencies of Electronic Learning skills?

To answer the above question, mean scores, and standard deviations for female teachers' responses were calculated. The findings are shown in Table 3 below.

Table 3 reveals that mean scores were ranging between (2.52 and 2.92).

The networks and internet use skills were at the top of the list with the highest mean score. The skills of the design and managing the Electronic Learning curricular were at the list's last. The average practice and knowledge levels of the whole efficiencies were moderate. The mean score was (2.78).

\subsection{Results Related to the Second Question}

Findings related to the second question: What are the female teachers' efficiencies of Electronic Learning that have the highest and the lowest practice and knowledge indicators?

To answer the above question, frequencies and mean scores were used to determine female teachers' practice and knowledge degree of those efficiencies of Electronic Learning. Findings are shown in Table 4 and Table 5 below.

Table 3. Means And Standard Deviations Of Efficiencies Of Electronic Learning Practice And Knowledge Level Among Female Teachers

\begin{tabular}{|c|c|c|c|}
\hline Efficiencies Domains & Mean & Std. D. & practice and knowledge Level \\
\hline The Networks \& Internet Use Skills & 2.92 & 1.092 & Moderate \\
\hline The Electronic Learning Culture Knowledge & 2.86 & 1.011 & Moderate \\
\hline The Computers Use Skills & 2.83 & 1.150 & Moderate \\
\hline The Design And Managing The Electronic Learning Curricular Skills & 2.52 & 1.082 & Low \\
\hline Average & 2.78 & 0.979 & Moderate \\
\hline
\end{tabular}

Table 4. The Highest Indicators Of Efficiencies Of Electronic Learning Practiced And Knowledge By Female Teachers

\begin{tabular}{|c|c|c|c|c|c|}
\hline Rank & Items & Mean & Std.D & Level & Domain \\
\hline 1 & $\begin{array}{l}\text { Contacting To The Internet Via (Sim Card, Landline Or } \\
\text { Wirelessly). }\end{array}$ & 3.59 & 1.226 & High & The Networks \& Internet Use \\
\hline 2 & $\begin{array}{l}\text { Running The Computer And Using The Windows } \\
\text { Operating System. }\end{array}$ & 3.49 & 1.257 & High & The Computers Use \\
\hline 3 & $\begin{array}{l}\text { The Differences Between Traditional Education And } \\
\text { Electronic Learning. }\end{array}$ & 3.34 & 1.120 & Medium & The Electronic Learning Culture Knowledge \\
\hline 4 & $\begin{array}{l}\text { Connecting The Computer With The Internet Service And } \\
\text { Browsing The Web Pages Via Any Browser. }\end{array}$ & 3.21 & 1.293 & Medium & The Networks \& Internet Use \\
\hline 5 & The Benefits And Disadvantages Of Electronic Learning. & 3.11 & 1.145 & Medium & Electronic Learning Culture Knowledge \\
\hline 6 & $\begin{array}{l}\text { Creating And Organizing The Folders And Installing And } \\
\text { Removing The Programs. }\end{array}$ & 3.06 & 1.291 & Medium & The Computers Use \\
\hline 7 & $\begin{array}{l}\text { Using The Storage Units Such As The CDs And An } \\
\text { External Usb Storage Media. }\end{array}$ & 3.06 & 1.350 & Medium & The Computers Use \\
\hline 8 & $\begin{array}{l}\text { Running The Sound Clips And Educational Videos Which } \\
\text { In Web Sites. }\end{array}$ & 3.03 & 1.321 & Medium & The Networks \& Internet Use \\
\hline 9 & The Concept And Objectives Of Electronic Learning. & 3.03 & 1.112 & Medium & Knowledge of Electronic Learning Culture \\
\hline 10 & $\begin{array}{l}\text { Using The Menus Bar Which In Web Browsers And Other } \\
\text { Chat Programs. }\end{array}$ & 2.95 & 1.271 & Medium & The Networks \& Internet Use \\
\hline
\end{tabular}


Table 5. The Lowest Indicators Of Efficiencies Of Electronic Learning Practiced And Knowledge By Female Teachers

\begin{tabular}{|c|l|c|c|c|l|}
\hline Rank & Items & Mean & Std.D & Level & Domain \\
\hline 1 & $\begin{array}{l}\text { The Tools And Programs Of An Instructional Content } \\
\text { Authoring. }\end{array}$ & 2.57 & 1.184 & Low & $\begin{array}{l}\text { Knowledge of Electronic Learning } \\
\text { Culture }\end{array}$ \\
\hline 2 & $\begin{array}{l}\text { Determining The Steps To Design Electronic Lesson And } \\
\text { Determining The Desired Objectives From It. }\end{array}$ & 2.55 & 1.176 & Low & $\begin{array}{l}\text { The Design And Managing The } \\
\text { Electronic Learning Curricular Skills }\end{array}$ \\
\hline 3 & $\begin{array}{l}\text { Supporting E-Content By Suitable Corrective Methods } \\
\text { For Female Students And The Curriculum. }\end{array}$ & 2.52 & 1.201 & Low & $\begin{array}{l}\text { The Design And Managing The } \\
\text { Electronic Learning Curricular Skills }\end{array}$ \\
\hline 4 & $\begin{array}{l}\text { Determining The Suitability Of Converting The } \\
\text { Curriculum Content To Electronic Tutorials. }\end{array}$ & 2.52 & 1.147 & Low & $\begin{array}{l}\text { The Design And Managing The } \\
\text { Electronic Learning Curricular Skills }\end{array}$ \\
\hline 5 & $\begin{array}{l}\text { Compressing And Extracting The Files By The } \\
\text { Specialized Programs. }\end{array}$ & 2.50 & 1.225 & Low & The Computers Use \\
\hline 7 & $\begin{array}{l}\text { Converting The Paper Book Content To An E-Book And } \\
\text { Multimedia Lessons. }\end{array}$ & 2.48 & 1.186 & Low & $\begin{array}{l}\text { The Design And Managing The } \\
\text { Electronic Learning Curricular Skills }\end{array}$ \\
\hline 8 & $\begin{array}{l}\text { Designing, Building, And Evaluating The Electronic } \\
\text { Anameworks And Exams. }\end{array}$ & 2.48 & 1.171 & Low & $\begin{array}{l}\text { The Design And Managing The } \\
\text { Electronic Learning Curricular Skills }\end{array}$ \\
\hline 9 & $\begin{array}{l}\text { Determine The Appropriate Feedback Pattern And } \\
\text { Managing Electronic Dialogues. }\end{array}$ & 2.40 & 1.157 & Low & $\begin{array}{l}\text { The Design And Managing The } \\
\text { Electronic Learning Curricular Skills }\end{array}$ \\
\hline 10 & $\begin{array}{l}\text { Designing, Producing, And Evaluating The E-Lessons By } \\
\text { Using Authoring Tools. }\end{array}$ & 2.37 & 1.103 & Low & $\begin{array}{l}\text { The Design And Manging The } \\
\text { Electronic Learning Curricular Skills }\end{array}$ \\
\hline
\end{tabular}

Table 4 above reveals that efficiencies of Electronic Learning' practice and knowledge of female teachers were either high or moderate. The highest degrees of efficiencies of Electronic Learning use were as follow:

The first highest mean score was (3.59) which was belonging to the efficiency of Networks and Internet Use, that which it was "Contacting to the internet via (sim card, landline or wirelessly)", whereas the second-high mean score was (3.49) which was related to the efficiency of the computers use, that which it was "Running the computer and using the Windows operating system”. In the other hand, Table 5 reveals the lowest indicators of efficiencies of Electronic Learning practiced and knowledge by female teachers.

Table 5 above reveals that efficiencies of Electronic Learning' practice and knowledge of female teachers were either low. The lowest degrees of efficiencies of Electronic Learning use were as follow:

The first lowest mean score was (2.37) which was belonging to the efficiency of the design and managing the Electronic Learning curricular skills, that which it was "Designing, producing, and evaluating the E-lessons by using authoring tools", whereas the second-low mean score was (2.40) which was related to the efficiency of the design and managing the Electronic Learning curricular skills too, that which it was "Determine the appropriate feedback pattern and managing electronic dialogues”.

\subsection{Results Related to the Third Question}

Are there any statistically significant variances and differences $(\alpha=0.05)$ in the degrees of the female teacher's knowledge and practice at Al- Hodaidah schools due to the type of academic specialization, types of Academic Qualifications, and Electronic Learning training courses?

To answer the above question, mean scores and standard deviations responses for efficiencies of Electronic Learning' knowledge and practice degree of female teachers at Al-Hodaidah city schools were calculated. Table 6 demonstrates the results. To answer the third question, means and standard deviations of sample responses for each domain were computed. Table 7 demonstrates the results.

Table 6. Efficiencies' Practice And Knowledge Degrees Among Female Teachers

\begin{tabular}{|c|c|c|c|c|c|c|c|}
\hline \multicolumn{2}{|c|}{ Variables } & & $\begin{array}{l}\text { Computers } \\
\text { Use Skills }\end{array}$ & $\begin{array}{c}\text { Networks \& } \\
\text { Internet Use Skills }\end{array}$ & $\begin{array}{l}\text { Electronic Learning } \\
\text { Culture Knowledge }\end{array}$ & $\begin{array}{c}\text { The Design and Managing The } \\
\text { Electronic Learning Curricular Skills }\end{array}$ & $\begin{array}{l}\text { Total } \\
\text { Degree }\end{array}$ \\
\hline \multirow{4}{*}{$\begin{array}{c}\text { Type of } \\
\text { Academic } \\
\text { Specialization }\end{array}$} & \multirow{2}{*}{ Scientific } & Mean & 3.168 & 3.093 & 3.054 & 2.709 & 3.006 \\
\hline & & Std. d. & 1.079 & 1.058 & 0.965 & 1.062 & 0.951 \\
\hline & \multirow{2}{*}{ Humanistic } & Mean & 2.458 & 2.736 & 2.651 & 2.311 & 2.539 \\
\hline & & Std. d. & 1.115 & 1.104 & 1.023 & 1.071 & 0.957 \\
\hline \multirow{6}{*}{$\begin{array}{c}\text { Types of } \\
\text { Academic } \\
\text { Qualifications }\end{array}$} & \multirow{2}{*}{ Diploma } & Mean & 2.460 & 2.489 & 2.605 & 2.273 & 2.457 \\
\hline & & Std. d. & 1.322 & 1.233 & 1.214 & 1.208 & 1.114 \\
\hline & \multirow{2}{*}{ Bachelor } & Mean & 2.909 & 3.032 & 2.919 & 2.568 & 2.857 \\
\hline & & Std. d. & 1.080 & 1.032 & 0.944 & 1.043 & 0.925 \\
\hline & \multirow{2}{*}{$\begin{array}{l}\text { Master or } \\
\text { Above }\end{array}$} & Mean & 3.600 & 3.325 & 3.325 & 3.150 & 3.350 \\
\hline & & Std. d. & 1.068 & 0.806 & 0.862 & 0.870 & 0.853 \\
\hline \multirow{4}{*}{ Training } & \multirow{2}{*}{ Yes } & Mean & 3.393 & 3.258 & 3.202 & 2.900 & 3.188 \\
\hline & & Std. d. & 0.918 & 0.978 & 0.881 & 0.979 & 0.859 \\
\hline & \multirow{2}{*}{ No } & Mean & 2.477 & 2.713 & 2.649 & 2.280 & 2.530 \\
\hline & & Std. d. & 1.143 & 1.111 & 1.032 & 1.079 & 0.968 \\
\hline
\end{tabular}


Table 6 above reveals variation in the means and standard deviations of efficiencies of Electronic Learning' knowledge and practice degrees among female teachers. This variation is due to the variance of the type of academic specialization, types of Academic Qualifications, and training in Electronic Learning. In order to understand the statistical significances of these differences, Mann-Whitney U, Kruskal-Wallis Test, T-Test, and One-Way ANOVA were used for each domain for presenting the differences to answer the third question, and test the hypotheses related as presented and shown below:

\subsubsection{Results Related to the First Hypothesis}

First Hypothesis: "There are no significant differences at $(\alpha=0.05)$ the 1 nd and 2 nd axises degree of the Electronic Learning efficiencies and their dimensions about (the computers use skills, and the networks and internet use skills) for female teachers at Al-Hodaidah city schools due to the type of academic specialization and attendance on training courses' variables.”

To prove that the first and second subsections of the first hypothesis, the researcher used (Mann-Whitney U) to test it, as shown in Table 7 and Table 8. Mann-Whitney U test was used to determine if there are significant

statistical differences between (the scientific and the humanistic' specializations) for the first subsection, and also the differences between (those who have attended and who have not attended training courses on Electronic Learning) for the second subsection, on the two main axises that contains Electronic Learning efficiencies, as shown in Table 7 and Table 8 . Table 7 below shows the Mann-Whitney $U$ test results, to determine if there are significant statistical differences between Scientific and Humanistic' specializations on two main axises that contain Electronic Learning efficiencies.

All the mean ranks of Scientific response are bigger than the Humanistic response ranks in the cases of the two main axises, and the significance probability column reveals to be less than 0.05 in the cases of two main axises components (the computers use skills, and the networks and internet use skills), meaning that there are significant statistical differences between scientific and humanistic respondents as two independent variables.

So, we reject the null and accept alternative hypothesis that there are a significance differences between scientific and humanistic respondents as two independent variables, so that the first subsection of the first hypothesis is rejected. On the other hand, Table 8 below shows the results of the Mann-Whitney $U$ test, to determine if there are significant statistical variances and differences between the respondents of who have attended and who have not attended training courses on two main axises that contain Electronic Learning efficiencies.

The mean ranks of who have attended training courses response are bigger than the who have not attended training courses response ranks in the cases of the two main axises, and the significance probability column reveals to be less than 0.05 in the cases of the two main axises components (the computers use skills, and the networks and internet use skills), meaning that there are significant statistical variances and differences between the respondents of who have attended and who have not attended training courses as two independent variables. So, we reject the null and accept alternative hypothesis that there are a significance differences between who have attended training courses and who have not attended training courses respondents as two independent variables, so that the second subsection of the first hypothesis is rejected. This means that the first hypothesis is rejected.

\subsubsection{Results Related to the Second Hypothesis}

Second Hypothesis: "There are no significant differences at $(\alpha=0.05)$ in the 1 st and 2 nd axises degree of the Electronic Learning efficiencies and their dimensions about (the computers use skills, and the networks and internet use skills) for female teachers at Al-Hodaidah city schools due to the types of Academic Qualifications.”

Table 7. Mann-Whitney U-test Between 1st, and 2nd's Axises of Electronic Learning Efficiencies and Type of Academic Specialization

\begin{tabular}{|c|c|c|c|c|c|c|}
\hline The Axises of Efficiencies & Type of Academic Specialization & $\mathrm{N}$ & Mean Rank & Sum of Ranks & Mann-Whitney U & $\begin{array}{c}\text { Asymp. } \\
\text { Sig. (2-tailed) }\end{array}$ \\
\hline \multirow{3}{*}{$\begin{array}{l}\text { The 1st Axis of Electronic } \\
\text { Learning Efficiencies } \\
\text { (The Computers Use Skills) }\end{array}$} & Scientific & 91 & 102.46 & 9324.00 & \multirow{3}{*}{2415.000} & \multirow{3}{*}{.000} \\
\hline & Humanistic & 83 & 71.10 & 5901.00 & & \\
\hline & Total & 174 & & & & \\
\hline \multirow{3}{*}{$\begin{array}{l}\text { The 2nd Axis of Electronic } \\
\text { Learning Efficiencies } \\
\text { (The Networks \& Internet } \\
\text { Use Skills) }\end{array}$} & Scientific & 91 & 95.36 & 8678.00 & \multirow{3}{*}{3061.000} & \multirow{3}{*}{.031} \\
\hline & Humanistic & 83 & 78.88 & 6547.00 & & \\
\hline & Total & 174 & & & & \\
\hline
\end{tabular}

Table 8. Mann-Whitney U-test Between 1st, and 2nd's Axises of Electronic Learning Efficiencies and Attendance on Training Courses

\begin{tabular}{|c|c|c|c|c|c|c|}
\hline \multicolumn{2}{|c|}{$\begin{array}{l}\text { Did You Attend Any Educational Courses Related to Electronic } \\
\text { Learning? }\end{array}$} & $\mathrm{N}$ & Mean Rank & Sum of Ranks & Mann-Whitney U & $\begin{array}{l}\text { Asymp. } \\
\text { Sig. (2-tailed) }\end{array}$ \\
\hline \multirow{3}{*}{$\begin{array}{l}\text { The 1st Axis of Electronic Learning Efficiencies } \\
\text { (The Skills of The Computers Use) }\end{array}$} & No & 107 & 72.01 & 7705.00 & \multirow{3}{*}{1927.000} & \multirow{3}{*}{.000} \\
\hline & Yes & 67 & 112.24 & 7520.00 & & \\
\hline & Total & 174 & & & & \\
\hline \multirow{3}{*}{$\begin{array}{l}\text { The 2nd Axis of Electronic Learning Efficiencies } \\
\text { (The Skills of the Networks \& Internet Use) }\end{array}$} & No & 107 & 77.62 & 8305.00 & \multirow{3}{*}{2527.000} & \multirow{3}{*}{.001} \\
\hline & Yes & 67 & 103.28 & 6920.00 & & \\
\hline & Total & 174 & & & & \\
\hline
\end{tabular}


Table 9 below shows the results of Kruskal-Wallis test to determine if there is the significant statistical difference between the academic qualification of respondents that contain three categories (Diploma - bachelor - master or above) and two main axises that contain Electronic Learning efficiencies.

All the mean ranks of master or above response are bigger than the diploma response ranks in the cases of the two main axises, and the significance probability column reveals to be less than 0.05 in the cases of the two main axises components (the computers use skills, and the networks and internet use skills), meaning that there are significant statistical differences between the groups (Diploma - bachelor - master or above).

So, we accept the hypothesis of alternative and reject the null hypothesis that there is no significance difference between the 1st and 2nd axises efficiencies components as the three independent variables.

This means that the second hypotheses are rejected.

\subsubsection{Results Related to the Third Hypothesis}

Third Hypothesis: "There are no significant differences at $(\alpha=0.05)$ in the third axis degree of the Electronic Learning efficiencies, which its dimensions about (the knowledge of Electronic Learning culture) for female teachers at Al-Hodaidah city schools due to the type of academic specialization, and Attendance on training courses' variables."

To prove that the first and second subsections of the third hypothesis, the researcher used the T-Test to test it, as shown in tables Table 10 and Table 11 . The Table 10 results of $\mathrm{T}$-Test to examine the differences in the Electronic Learning culture knowledge efficiency degrees of female teachers at Al-Hodaidah city schools, according to the variable of the type of academic specialization.

Table 10 showed that there are statistically significant differences at the level of significance of the knowledge from the female teachers' perspective in the field of Electronic Learning culture attributed to the type of academic specialization variable in favour of the scientific specialization, because the mean for the degree of Electronic Learning culture knowledge was (3.054) for the group that have scientific specialization while it was (2.651) for the group that have Humanistic specialization. So, the female teachers of the scientific specialization' knowing of the Electronic Learning culture is higher than Humanistic specialization, and this finding may be because of the fact that the Electronic Learning culture represented by the items of this field are clearer to the scientific specialization.

So, the first subsection in the third hypothesis is rejected, because the significance probability column reveals to be less than 0.05 . In the other hand, the Table 11 results of T-Test to examine the differences in the Electronic Learning culture knowledge degrees of female teachers at Al-Hodaidah city schools, according to the variable of attendance on training courses on Electronic Learning.

Table 11 showed that there are statistically significant differences at the level of significance of the knowledge from the female teachers' perspective in the field of Electronic Learning culture attributed to attendance on training courses variable in favor of the female teachers who have received training courses on Electronic Learning.

The degree of Electronic Learning culture knowledge was higher for the female teachers who have attended a training course on Electronic Learning with a mean (3.054) and (2.651) for those who have not attended training courses on Electronic Learning. So, the second subsection in the third hypothesis is rejected, because the significance probability column reveals to be less than 0.05 , this means that the third hypothesis is rejected.

Table 9. Kruskal-Wallis Test Between 1st, and 2nd's Axises of Electronic Learning Efficiencies and Academic Qualification Type

\begin{tabular}{|c|c|c|c|c|c|}
\hline Axises & Academic Qualification Type & $\mathrm{N}$ & Mean Rank & Kruskal-Wallis Test & Asymp. Sig. (2-tailed) \\
\hline \multirow{4}{*}{$\begin{array}{l}\text { The 1st Axis of Electronic Learning } \\
\text { Efficiencies } \\
\text { (The Skills of The Computers Use). }\end{array}$} & Diploma & 37 & 70.61 & \multirow{4}{*}{6.530} & \multirow{4}{*}{.038} \\
\hline & Bachelor & 133 & 91.23 & & \\
\hline & Master or Above & 4 & 119.63 & & \\
\hline & Total & 174 & & & \\
\hline \multirow{4}{*}{$\begin{array}{l}\text { The 2nd Axis of Electronic Learning } \\
\text { Efficiencies } \\
\text { (The Skills of the Networks \& } \\
\text { Internet Use). }\end{array}$} & Diploma & 37 & 69.15 & \multirow{4}{*}{6.525} & \multirow{4}{*}{.038} \\
\hline & Bachelor & 133 & 92.06 & & \\
\hline & Master or Above & 4 & 105.50 & & \\
\hline & Total & 174 & & & \\
\hline
\end{tabular}

Table 10. T-Test Between 3nd Axis Of Electronic Learning Efficiencies And Type Of Academic Specialization

\begin{tabular}{|c|c|c|c|c|c|c|c|}
\hline $\begin{array}{c}\text { The 3rd Axis of Electronic Learning Efficiencies } \\
\text { (The Knowledge OF Electronic Learning Culture) }\end{array}$ & $\mathrm{N}$ & Mean Rank & Std. Deviation & $\mathrm{t}$ & $\begin{array}{c}\text { df } \\
\text { Sig. (2-tailed) }\end{array}$ \\
\hline The Type of Academic Specialization & Scientific & 91 & 3.054 & .965 & 2.675 & 172 & $.008 *$ \\
\hline
\end{tabular}

${ }^{*} \mathrm{p} \leq(0.05)$

Table 11. T-Test Between the 3rd Axis Of Electronic Learning Efficiencies And Attendance On Training Courses

\begin{tabular}{|l|c|c|c|c|c|c|}
\hline \multicolumn{2}{|l|}{$\begin{array}{l}\text { The 3rd Axis OF Electronic Learning Efficiencies } \\
\text { (The Knowledge Of Electronic Learning Culture) }\end{array}$} & $\mathrm{N}$ & $\begin{array}{c}\text { Mean } \\
\text { Rank }\end{array}$ & $\begin{array}{c}\text { Std. } \\
\text { Deviation }\end{array}$ & \multicolumn{1}{c|}{$\begin{array}{c}\text { Asymp. } \\
\text { Sig. (2-tailed) }\end{array}$} \\
\hline \multirow{2}{*}{ Attendance on Training Courses } & No & 107 & 2.649 & 1.032 & \multirow{2}{*}{$.000 *$} \\
\cline { 2 - 5 } & Yes & 67 & 3.201 & 0.881 & -3.633 \\
\hline
\end{tabular}




\subsubsection{Results Related to the Fourth Hypothesis}

Fourth Hypothesis: "There are no significant differences at $(\alpha=0.05)$ in the third axis degree of the Electronic Learning efficiencies, which its dimensions about (the knowledge of Electronic Learning culture) for female teachers at Al-Hodaidah city schools due to types of Academic Qualifications.”

The researcher used (One-Way ANOVA) to test the fourth hypothesis. Table 12, Table 13 show the frequencies, means and standard deviations of female teachers' knowledge of Electronic Learning culture due to the Academic Qualifications' Type, and the result of One-Way ANOVA test. Firstly, Table 12 show the numbers, means, and standard deviations of female teachers' knowledge of Electronic Learning culture due to the types of Academic Qualifications.

Sub-Scale Groups of types of Academic Qualifications to the 3rd axis of Electronic Learning efficiencies.

Table 13 shows that there are no significant differences at $(\alpha=0.05)$ in the knowledge degree of Electronic Learning culture of female teachers due to the types of Academic Qualifications, because the significance probability column reveals to be above than 0.05 in the third axis components case (the knowledge of Electronic Learning culture), meaning that no significant differences between the three sub- groups (Diploma - bachelor - master or above). So, we reject alternative hypothesis and accept the null hypothesis that there is no significance difference between the third axis efficiency components as the three independent variables. This means that the fourth hypothesis is accepted.

\subsubsection{Results Related to the Fifth Hypothesis}

Fifth Hypothesis: "There are no significant differences at $(\alpha=0.05)$ in the 4 th axis degree of the Electronic Learning efficiencies, which its dimensions about (the skills of design and managing the Electronic Learning curricular) for female teachers at Al- Hodaidah city schools due to the type of academic specialization and attendance on training courses' variables.”

To prove that the first and second subsections of the fifth hypothesis, the researcher used the (Mann-Whitney U test) to test it, as shown in Table 14 and Table 15. Table 14 below shows the results of the Mann-Whitney U test, to determine if there are significant statistical differences between Scientific and Humanistic' academic specializations on the 4th axis.

The significance probability column reveals to be less than 0.05 in the 4th axis components case (the skills of design and managing the Electronic Learning curricular), meaning that there are significant statistical differences between Scientific and Humanistic respondents as two independent variables.

All the mean ranks of Scientific response are bigger than the Humanistic response ranks in the 4th axis components case, which means that there are significant statistical differences between two sub-groups shown by the significance probability, which is considerably less than (0.05) threshold. So, we reject the null and accept alternative hypothesis that there are a significance differences between Scientific and Humanistic respondents as two independent variables, so that the first subsection of the fifth hypothesis is rejected. In the other hand, Table 15 below shows the results of the Mann-Whitney U test, to determine if there are significant statistical variances and differences between the respondents of who have attended and who have not attended training courses on the 4th axis.

The significance probability column reveals to be less than 0.05 in the 4th axis components case (the skills of design and managing the Electronic Learning curricular), meaning that there are significant statistical differences between the respondents of who have attended and who have not attended training courses as two independent variables. The mean ranks of who have attended training courses response are bigger than the who have not attended training courses response ranks in the 4th axis components case, which means that there are significant statistical differences between two sub- groups shown by the significance probability, which is considerably less than (0.05) threshold.

Table 12. Sub-Scale Groups Of Types Of Academic Qualifications To The 3rd Axis Of Electronic Learning Efficiencies

\begin{tabular}{|l|l|c|c|c|}
\hline The 3rd Axis of Electronic Learning Efficiencies & The Types of Academic Qualifications & N & M & SD \\
\hline \multirow{4}{*}{ (The Knowledge of Electronic Learning Culture) } & Diploma & 37 & 2.605 & 1.214 \\
\cline { 2 - 5 } & Bachelor & 133 & 2.919 & 0.944 \\
\cline { 2 - 5 } & Master or Above & 4 & 3.325 & 0.862 \\
\cline { 2 - 5 } & Total & 174 & 2.862 & 1.011 \\
\hline
\end{tabular}

Table 13. One-Way ANOVA Test Between The 3rd Axis Of Electronic Learning Efficiencies And Types Of Academic Qualifications

\begin{tabular}{|l|l|c|c|c|c|c|}
\hline The 3rd Axis of Electronic Learning Efficiencies & Sources of variance & Squares Sum & D.F. & Mean Square & F & Asymp. Sig. (2-tailed) \\
\hline \multirow{3}{*}{ (The Knowledge of Electronic Learning Culture) } & Between Groups & 3.723 & 2 & 1.861 & 1.840 & .162 \\
\cline { 2 - 8 } & Within Groups & 172.969 & 171 & 1.012 & & \\
\cline { 2 - 8 } & Total & 176.692 & 173 & & & \\
\hline
\end{tabular}

*Significant at $(\alpha=0.05)$.

Table 14. Mann-Whitney U-Test Between 4nd Axis Of Electronic Learning Efficiencies And Academic Specialization Variable

\begin{tabular}{|l|l|c|c|c|c|c|}
\hline $\begin{array}{l}\text { The 4th Axis of Electronic Learning Efficiencies } \\
\text { (The Skills of Design and Managing the Electronic Learning Curricular) }\end{array}$ & $\mathrm{N}$ & Mean Rank & Sum of Ranks & Mann-Whitney U & $\begin{array}{c}\text { Asymp. } \\
\text { Sig. (2-tailed) }\end{array}$ \\
\hline \multirow{4}{*}{ The Type of Academic Specialization } & Scientific & 91 & 97.12 & 8837.50 & & \multirow{2}{*}{2} \\
\cline { 2 - 6 } & Humanistic & 83 & 76.96 & 6387.50 & \multirow{2}{*}{2901.500} & .008 \\
\cline { 2 - 5 } & Total & 174 & & & & \\
\hline
\end{tabular}


Table 15. Mann-Whitney U-Test Between 4nd Axis Of Electronic Learning Efficiencies And Attendance On Training Courses Variable

\begin{tabular}{|l|l|c|c|c|c|}
\hline \multicolumn{2}{|l|}{$\begin{array}{l}\text { The 4th Axis of Electronic Learning Efficiencies } \\
\text { (The Skills of Design and Managing the Electronic Learning Curricular) }\end{array}$} & $\mathrm{N}$ & Mean Rank & Sum of Ranks & Mann-Whitney U \\
\hline \multirow{3}{*}{ Attendance on Training Courses } & No & 107 & 76.065 & 8139.00 & Asymp. \\
\cline { 2 - 6 } & Yes & 67 & 105.761 & 7086.00 \\
\cline { 2 - 6 } & Total & 174 & & & 2361.000 \\
\end{tabular}

Table 16. Kruskal-Wallis Test Between 4st Axis of Electronic Learning Efficiencies and Academic Qualification Type

\begin{tabular}{|c|c|c|c|c|c|c|c|}
\hline $\begin{array}{l}\text { The 4th Axis of Electronic Learning } \\
\text { Efficiencies }\end{array}$ & $\begin{array}{c}\text { Academic } \\
\text { Qualification Type } \\
\end{array}$ & $\mathrm{N}$ & Mean Rank & Chi-Square & $\mathrm{df}$ & $\begin{array}{c}\text { Kruskal-Wallis } \\
\text { Test } \\
\end{array}$ & $\begin{array}{c}\text { Asymp. } \\
\text { Sig. (2-tailed) }\end{array}$ \\
\hline \multirow{4}{*}{$\begin{array}{l}\text { (The Skills of Design And Managing } \\
\text { The Electronic Learning Curricular). }\end{array}$} & Diploma & 37 & 74.76 & \multirow{4}{*}{4.146} & \multirow{4}{*}{2} & \multirow{4}{*}{4.146} & \multirow{4}{*}{.126} \\
\hline & Bachelor & 133 & 90.15 & & & & \\
\hline & Master or Above & 4 & 117.13 & & & & \\
\hline & Total & 174 & & & & & \\
\hline
\end{tabular}

So, we reject the null and accept alternative hypothesis that there are a significance differences between who have attended training courses and who have not attended training courses respondents as two independent variables, so that the second subsection of the fifth hypothesis is accepted. This means that the fifth hypothesis is rejected.

\subsubsection{Results Related to the Sixth Hypothesis}

Sixth Hypothesis: "There are no significant differences at $(\alpha=0.05)$ in the 4 th axis degree of the Electronic Learning efficiencies, which its dimensions about (the skills of design and managing the Electronic Learning curricular) for female teachers at Al- Hodaidah city schools due to the types of Academic Qualifications.”

To prove that the sixth hypothesis, the researcher used the (Kruskal-Wallis test) to test it. Kruskal-Wallis test was used to determine if there are significant statistical differences between (Diploma, Bachelor, and Master or above' Academic Qualifications) and the 4th axis efficiency that contains the components of the skills of design and managing the Electronic Learning curricular, as shown in Table 16.

Table 16 shows the Kruskal-Wallis test results to determine if there are significant statistical differences between the Academic qualification of respondents that contain three categories (Diploma - bachelor - master or above) and components of the 4th axis efficiency of Electronic Learning efficiencies.

The significance probability column reveals to be above than 0.05 in the 4th axis components case (the skills of design and managing the Electronic Learning curricular), meaning that no significant differences between the three sub- groups (diploma - bachelor - master or above). So, we reject the alternative hypothesis and accept the null hypothesis that there is no significance difference between the 4th axis efficiency components as the three independent variables. This means that the sixth hypothesis is accepted.

\section{Discussion}

This research sought to identify the availability of Electronic Learning efficiencies that which the female teachers at Al-Hodaidah city schools possess. Generally, the results of this study suggest that the female teachers at Al-Hodaidah city schools possess the Electronic Learning efficiencies in all axises with moderate level.

\subsection{The Findings Related Discussion to the First Question}

Table 3 in the indicated that the networks and internet use skills efficiencies were in the first rank but moderate level. Their practice and knowledge level by female teachers was (2.92). This finding is in agreement with the finding of [44], and [39] were in the first rank [35].

At the list bottom, came the design and managing the Electronic Learning curricular skills domain with a mean score that was (2.52), that is meaning in the lowest level. At the same time, this finding is in agreement with the finding of [41], [28], [39], and [13] was in the bottom of the list rank but moderate level [35].

Afterward, the average mean score of the overall instrument of female teachers' degrees of practice and knowledge of all efficiencies of Electronic Learning involved in the present study was (2.78). So it was medium level. Again, That is agreement with the finding of Al-[44], [40], [46], [28], [39], [50], [52], and [13]. Such that result, it can be considered good, because awareness level of female teachers is encouraging and patients, although weak institutional capacities, and a lack of the increased investment into the traditional education and electronic by the government. This suggests that to female teachers' capability to promote and implement all the Electronic Learning efficiencies which they owned.

Those capabilities may be owned during some training programs and courses, because of personal attention to them. This, in turn, provides female teachers the condition to develop their skills of electronic learning efficiencies. On the other hand, there had been changing in the knowledge and efficiencies of female teachers, due to the spread of the internet, which has improved significantly, which in turn helped them expand their knowledge and skills. Furthermore, the most devices such computers, notebooks, and tablets have become available affordable and accessible to all, and that led to facilitate their skills and tasks in the Educational and public life aspects.

\subsection{Discussion of the Findings Related to the Second Question}

Firstly, Table 4 that the practice and knowledge degree of Electronic Learning efficiencies by female teachers were ranging between high, moderate. The highest practice and knowledge degree were for efficiencies of 
Contacting to the internet via (sim card, landline or wirelessly), its mean score was (3.59). The second highest practice and knowledge degree were for efficiencies of running the computer and using the Windows operating system, its mean score was (3.49). Then, the moderate practice and knowledge degree efficiencies (3.34) was that related to the Electronic Learning Culture knowledge which was the knowing The Differences Between Traditional Education and Electronic Learning. This finding attributable to the expansion in use the networks and internet skills, and the computers skills' efficiencies in the most of the daily life aspects, but with positive effect in the knowledge of Electronic Learning.

Secondly, Table 5 that the practice and knowledge degree of Electronic Learning efficiencies by female teachers were low. The lowest practice and knowledge degree were for efficiencies of designing, producing, and evaluating the E-lessons by using authoring tools, its mean score was (2.37). The second lowest practice and knowledge degree were for efficiencies of determining the appropriate feedback pattern and managing electronic dialogues, its mean score was (2.40), where both of them and most the efficiencies at Table 5 related to the design and managing the Electronic Learning curricular skills. This could be attributable to many causes, such as lack of motivation with the lack of technology skills due to lack of access to training, and lack of continuing practice with application in reality, which is important to these skills.

\subsection{The Findings Related Discussion to the Third Question}

Table 6 reveals an apparent variation in the mean scores and standard deviations of Electronic Learning efficiencies' practice and knowledge level of female teachers at Al-Hodaidah schools. This difference was due to the difference in the variables of study, viz., type of academic specialization, types of academic qualifications, and training in the field of Electronic Learning. For the sake of elucidating the significance of these differences, tests' Mann-Whitney U, Kruskal-Wallis, T-Test, and One-Way ANOVA were used for participants' responses to the four axises of Electronic Learning efficiencies in the study. As shown in the tables starting from the Table 7 and ending on Table 16. Besides, the results of the third question are presented according to the six tested hypotheses. These were used for analysis of responses to all instruments.

Mann-Whitney U and Kruskal-Wallis results showed that there were differences as shown in Table 7, Table 8, and Table 9. Because of academic specialization type, training courses, and types of academic qualifications in 1st, and 2nd's axises of Electronic Learning efficiencies, in favor of scientific specializations, who have attended training courses, and master or above qualification. For this reason, the first and second hypotheses are therefore rejected. The reason behind for these differences might be due to the length of time which spent by female teachers with the computer and the Internet, also to the provision of computer labs since early during their university studies, especially those who have scientific specializations, Master or above qualification, and who have attended training courses. This finding is in disagrees with the findings of [56], [57], [46], [28], and [50], but agreement with the findings of [58], and [52] in favor of master or above qualification ones; [44], [59], [48], and [52] in favor of who have attended training courses; also, agreement with the finding of [40], and [52] in favor of scientific specializations[46,55,56,57,58].

At the same time, T-Test and Mann-Whitney $\mathrm{U}$ results showed that there were differences as shown in Table 10, Table 11, Table 14 and Table 15, because of academic specialization type and training courses in 3st, and 4nd's axises of Electronic Learning efficiencies, in favor of scientific specializations and who have attended training courses. This finding is in disagrees the findings of [28], [48], and [50], but agreement with the finding of [60], and [44] in favor of who have attended training courses; and [39] in favor of scientific specializations ones. As a result, the third and fifth hypotheses are therefore rejected too $[59,60]$.

On the contrary, One-Way ANOVA and KruskalWallis results showed that there were no differences as shown in Table 13 and Table 16 because of the type of academic qualification in 3st, and 4nd's axises of Electronic Learning efficiencies, therefore, the fourth and sixth hypotheses are therefore accepted. One reason might be for this finding is because of all the participants of study have the same knowledge of the culture and experience in the design and management of Electronic Learning curriculum. Besides, that whatever the different the academic qualifications that they have, but they know the important of use Electronic Learning in improving the educational process, in particular for female students. This finding is in agreement with the finding of [40], [28], [50], and [51]; but in disagrees with the finding of [39] in favor of scientific ones.

\section{Conclusion and Recommendations}

The topic of Electronic Learning efficiencies is one of the important, and necessary topics for schools usually are affected in their development, particular in the issues of females' education in Yemeni schools. This paper reported the findings of a study designed to identify the availability of Electronic Learning efficiencies among Yemeni female teachers in $\mathrm{Al}$-Hodaidah city schools. Results of the present study may be helpful for the improvement of the performance of schools' female teachers in many directions. This study prepares the plan for a more substantial investigation of Yemeni female teachers' readiness to accept and adopt Electronic Learning to teach their female students. The results of this study suggest that the female teachers feel confident they are ready to use Electronic Learning. The findings showed that female teachers possess the efficiencies of Electronic Learning in all axes with medium level. The findings showed that female teachers possess the Electronic Learning efficiencies in the axis of The Skills of The Computers Use, the axis of The Skills of the Networks \& Internet Use, and The Knowledge of Electronic Learning Culture with medium level, and possess The Skills of Design and Managing the Electronic Learning Curricular with low level.

Based on the results of the present study, the researcher recommends: 
- The necessity of holding training sessions to empower the female teachers to give them the basic skills to help them design lessons electronically, also support and enrich the efficiencies which they have in using the computer and the Internet.

- Include Electronic Learning and its skills as a rapporteur in the curricula of all Yemeni universities in all Academic disciplines.

- Strengthen the prestige of the Electronic Learning at Ministry of Education in Yemen through reviewing its benefits to improve

- Education Systems in the others countries.

- Spread the culture of Electronic Learning through the means of social communication between members of the community to become part of the culture of education of the Yemeni society.

- Findings of the present study may be beneficial for the development of the performance of female teachers in many skills to facilitate the task of teaching, as the first step to change the current situation of the women education to the best.

- In order to gain more support from parents, families, and husbands of female teachers and female students in using Electronic Learning at home, more efforts and resources should be invested in them such as training programs.

Finally, it will also be necessary to conduct this study from the viewpoint of other stakeholders such as administrators, parents, and female students to ensure that the voices of everyone are heard and taken into consideration when decisions and progress are made besides this modern technology; so, this study recommends conducting other research and studies in the Electronic Learning field depended on different variables and samples.

\section{References}

[1] K. A. Nihuka and J. Voogt, "Collaborative e-learning course design: Impacts on instructors in the Open University of Tanzania," Australas. J. Educ. Technol., vol. 28, no. 2, pp. 232-248, Apr. 2012.

[2] G. Campaign and R. E. Fund, "make it right: Ending the Crisis in Girls’ Education,” 2011.

[3] E. Marshall, Six Things to Know About the Education in Yemen. 2016, p. 1.

[4] V. Sherbakov, Human Rights in Yemen. The Institute of General Pathology and Path physiology, Russian Academy of Sciences, Moscow, Russia, 2014.

[5] F. Darem, "Yemeni Women's Uphill Struggle for Education,” AlFanar Media, 2014

[6] P. Centre, "UNICEF calls for safety of schools in Yemen as the new school year opens,” www.unicef.org. p. 1, 2016.

[7] C. Sak-Colareza, M. Hammami, I. Neacșu, and L. Mihai, “E Learning Experiences In Non-European Countries (Syria And Turkey).”

[8] R. A. Omer and S. G. Alqwieder, "E-Learning Competencies Practice Level among Faculty Members at Najran University,” SJETR Journal., vol. Vol. 2, No, no. 1, 2016.

[9] T. So and P. M. C. Swatman, "E-Learning readiness of Hong Kong teachers,” Hong Kong IT Educ. Conf., no. February, pp. 6-8, 2007.

[10] H. M, "SIP AIP (e-Learning) Competencies (A112)," Society of Internet ProfessionalsTM (SIPTM) Haroon M, 2004. [Online]. Available:

http://www.sipgroup.org/resources/docs/a112_e_learning_compet enencies.pdf. [Accessed: 22-Dec-2016].
[11] M. Makoe, “Academics Going Mobile: Identifying New Roles For New Technologies,” in http://www.saide.org.za/, 2010, p. 21.

[12] M. Alkhawaldah, "The Impact of Using E-Learning on the Achievement of 3rd Primary Grade in the Syllabus of National and Social Education in Jordan and their Attitudes Towards it," Dirasat Educ. Sci., vol. 40, pp. 5, 1, 2013.

[13] N. AlHajya and M. Luz Guenaga, "The Extent to Which Teachers of Arabic Language in Al-Hisa Educational Directorate of Schools of Jordan Acquire E-Learning Competencies,” Int. Educ. Stud., vol. 9, no. 9, 2016.

[14] K. E. Murphrey, Theresa Pesl|Dooley, "Determining E-Learning Competencies: Using Centra[TM] to Collect Focus Group Data.," Q. Rev. Distance Educ., vol. 7, no. 1, pp. 75-82, 2006.

[15] W. Horton and K. Horton, E-learning Tools and Technologies. Indianapolis, IN: Wiley, 2003.

[16] R. Martens, R. Martens, J. Gulikers, and T. Bastiaens, "The Impact of Intrinsic Motivation on E-Learning in Authentic Computer Tasks,” J. Comput. Assist. Learn., vol. 20, no. 5, pp. 368-376, 2004.

[17] S. Kotzer and Y. Elran, "Learning and teaching with Moodlebased E-learning environments, combining learning skills and content in the fields of Math and Science \& Technology," in 1 st Moodle ResearchConference, 2012, p. 10.

[18] A. Jacobson, Michael J. Archodidou, "The Design of Hypermedia Tools for Learning: Fostering Conceptual Change and Transfer of Complex Scientific Knowledge.," J. Learn. Sci., vol. 9, no. 2, pp. 145-99, 2000.

[19] ELearningNC, "What is eLearning? eLearningNC.gov," eLearningNC.gov, 2016. [Online]. Available: http://www.elearningnc.gov/about_elearning/what_is_elearning/. [Accessed: 30-Dec-2016].

[20] M. Parkes, C. Reading, and S. Stein, “The Competencies Required For Effective Performance In A University E-Learning Environment," Australas. J. Educ. Technol., vol. 29, no. 6, pp. 777-791, 2014.

[21] V. Sebastian, M. Annika, and Z.-R. Olaf, "From Knowledge Transfer to Competence Development - a Case of Learning by Designing," in Proceedings of World Conference on Educational Multimedia, Hypermedia and Telecommunications, 2010, pp. 1416-1424.

[22] J. Trna and E. Trnová, "IBSE PROFILES-Modules in Science Teacher Education,” 2015, p. 5.

[23] J. M. Spector and I. de la Teja, "Competencies for Online Teaching. ERIC Digest.,” ERIC Clear. Inf. Technol. Syracuse NY. , 2001.

[24] Y. Gulbahar, “Competencies for e-Instructors: How to Qualify and Guarantee Sustainability,” Contemp. Educ. Technol., vol. 6, no. 2, pp. 140-154, 2015.

[25] P. C. M. Carril, M. G. Sanmamed, and N. Hernández Sellés, "Pedagogical roles and competencies of university teachers practicing in the E-learning environment,” Int. Rev. Res. Open Distance Learn., vol. 14, no. 3, pp. 462-487, 2013.

[26] Al-Megreen Abdullah, "The Fourth International Conference for e-learning and Distance Learning,” http://eli.elc.edu.sa/, 2015. [Online]. Available: http://eli.elc.edu.sa/2015/node/296. [Accessed: 29-Dec-2016].

[27] WAM - United Arab Emirates News Agency, "Women and ELearning' Conference to Mark Knowledge Day at Ajman University.," WAM - United Arab Emirates News Agency, 2010.

[28] S. Elagrami, “Mastery Level of E-Learning Competencies among Teachers of Technology in Schools of Gaza Governorate in the Light some Variables,” Najah Univ. Res. J., vol. 26, no. 8, p. 38, 2012.

[29] G. O. Ouma, F. M. Awuor, and B. Kyambo, "Evaluation of E-Learning Readiness in Secondary Schools in Kenya," World Appl. Program., no. 310, pp. 493-503, 2013.

[30] C. Bremer, Fit For E-learning? Trainings For E-learning Competencies. The conference proceedings of edulearn, 2010, p. 10.

[31] A. Salem, Technology of Education and E- Learning, 1st ed. Riyadh, KSA: Alroshd Bookshop, 2004.

[32] S. Agency, P. U. B. Date, P. U. B. Type, and E. Price, National Educational Technology Standards for Teachers: Preparing Teachers To Use Technology. Washington: PBS Teacher Line, 2002. 
[33] L. G. Thomas, "Information, Communications, and Educational Technology Standards For Students, Teachers, and School Leaders," pp. 1-24, 2009.

[34] D. Bjekić, R. Krneta, and D. Milošević, "Teacher education from e-learner to E-teacher: Master curriculum," Turkish Online J. Educ. Technol., 2010.

[35] K. Chang Barker, "eFaculty Competencies: An eTQM Case Study of Selection and Utilization," e-Learning Unit, p. 40, 2007.

[36] http://www.inacol.org/, National Standards for Quality Online Courses. Originally published in 2007 by the North American Council for Online Learni, 2011, p. 46.

[37] F. D. WILliAMS, “An Examination Of Competencies, Roles, And Professional Development Needs Of Community College Distance Educators Who Teach Mathematics," Unpublished Doctoral dissertation, the Florida state university, 2006.

[38] A. Jehlan, “Mathematics Teachers' Attitudes Towards The Use Of Distance Education In The Teaching Of Mathematics In Saudi Arabia," in The Second International Conference on E-learning and Distance Education, 2011, p. 36.

[39] M. Zahrani, "E-Learning competencies of secondary school teachers in al-Qurayyat governorate in the kingdom of Saudi Arabia," Umm Al Qura University, 2012.

[40] A. Al-Amri, "Electronic Llearning Competences and Their Availability Degree With The High School Teachers in Al Mekhwah Educational Governorate," Kingdom of Saudi Arabia, 2009.

[41] R. M. R. Kullab, "The degree of e-learning competencies of the computerized interactive learning (CIL) teachers at UNRWA schools in Gaza and its relationship to their attitudes," publisher, Gaza City, 2011.

[42] T. Omoniyi and A. Taofeek Quadri, "Perceived Competence of Nigerian Secondary Schools Teachers in the Use of Information and Communication Technology (ICT)," vol. 4, no. 10, 2013.

[43] Al-Maamari and Saif, "The Degree of Availability of the Competencies of Information and Communication technology with social studies teachers in the post Basic Education in Some Omani Governorates,” Int. J. Educ. Res. / Univ. The United Arab Emirates, vol. 34, pp. 60-92, 2013.

[44] N. A. Alkhawaldeh and M. Al-Mashaleh, "Islamic Education Teachers' Competencies for Electronic Learning," J. Educ. Psychol. Sci., vol. 10, pp. 187-208, 2009.

[45] H. Al-Domy, "The degree of appreciation of the science teachers to the importance of technological skills education to improve the professional performance," Damascus Univ. J., vol. 26, no. 3, pp. 439-481, 2010.

[46] B. Al-Barod, "The Extent to which Teachers of Secondary School in Gaza City have the Technological Competencies And Extent of the Practice of its, From the Teachers Perspective.," 2010.

[47] H. A. Bani Domi and H. M. Daradkah, "The Extent of Acquiring Computer Teachers' E-learning Compe- tencies at 'King Hamad's
Project Schools' in Bahrain,” J. Educ. Psychol. Sci., vol. 13, pp. 187-218, 2012.

[48] R. Al-Mihmadi, "The levels of Arabic language female teachers ability in Efficiencies of e-learning to teach it in a high school in the Holy Capita,” Umm Al Qura University, Makkah, 2012.

[49] A. Alahmari and L. Kyei-blankson, "Adopting and Implementing an E-Learning System for Teaching and Learning in Saudi Public K-12 Schools: The Benefits , Challenges , and Concerns," World J. Educ. Res., vol. 3, no. 1, pp. 11-32, 2016.

[50] F. Al-Masrouri and S. Al-Maamari, "The degree of availability of the competencies of information and communication technology with social studies teachers in the post basic education in some Omani governorates,” Int. J. Educ. Res. / Univ. The United Arab Emirates, no. 43, p. 33, 2013.

[51] F. Abo-Shmalh and S. Al-Gabor, "Determine the degree of practice teaching skills needed to use the Digital Learning Objects (DLO) from the viewpoint of Information and Communication Technology (ICT) teachers' at the secondary schools in the Gaza Strip,” Rashad Shawa Cult. Cent., pp. 1-7, 2013.

[52] E. Al-Astall, "The availability and use of the efficiencies of e-learning among Islamic education teachers at the secondary level and the difficulties that prevent it from their point of view," J. Al-Quds Open Univ. Res. Stud. Educ. Psychol., vol. 8, no. 2, pp. 321-362, 2014

[53] M. Taha, "Investigating the Success of E-Learning in Secondary Schools: The Case of the Kingdom of Bahrain," Brunel University, Department of Computer Science, 2014.

[54] V. Rambousek, J. Štípek, and R. Wildová, "ICT Competencies and their Development in Primary and Lower-secondary Schools in the Czech Republic,” Procedia - Soc. Behav. Sci., vol. 171, pp. 535-542, Jan. 2015.

[55] H. Uzunboylu and N. Tuncay, "E-learning divides in North Cyprus,” Asia Pacific Educ. Rev., vol. 10, no. 2, pp. 281-290, Jun. 2009.

[56] N. Azmi, "The Competences Of Teachers According To Their Roles In The Future With the Distance E-lectronic Education Systems," 2006.

[57] M. M. Barghout, "The necessary of Technological Skills to Implement the Approach of the Technological for Tenth Grade Students and the Degree of Practice of the Teachers to It," 2010.

[58] K. S. Al-Momani, "Technological Competencies of Teachers In the Irbid city From the Supervisors Viewpoint,” J. Sci. Humanit., vol. 5, no. 36, 2008.

[59] S. Al-Zahrani, "Availability of efficiencies of computer use among secondary school mathematics teachers," Umm Al Qura University, 2009.

[60] A.-S. and Bassem, "Degree of Possession and Exercising of The Technological Competencies Which Middle School Male and Female Teachers Owned," Master Thesis, vol. Jordan Uni, no. Amman, p. Jordan, 2005. 